\title{
MIRADAS DIVINAS: ELEMENTOS DE RESISTENCIA A LA COLONIZACIÓN DE LA PENÍNSULA IBÉRICA EN LAS EXPRESIONES RELIGIOSAS AFROECUATORIANA Y AFROBRASILEÑA
}

\author{
DIVINE GLANCES: ELEMENTS OF RESISTANCE TO THE IBERIAN \\ PENINSULA'S COLONIZATION IN AFRO-ECUADORIAN AND \\ AFRO-BRAZILIAN RELIGIOUS EXPRESSIONS
}

\author{
Syntia Alves ${ }^{*}$ y Rocío Pérez Gañán**
}

\begin{abstract}
Las huellas de los orígenes africanos en los pueblos esmeraldeños ecuatorianos pueden percibirse en sus expresiones religiosas. Estos elementos, poseedores de una identidad específica, se han constituido, a lo largo del tiempo, como espacios propios de resistencia a la imposición cultural de la colonización. Aunque la mayor parte de la población afroecuatoriana practica actualmente la religión católica, es posible rastrear en su religiosidad los componentes de resistencia que han permanecido activos sincréticamente y que se acercan, en algunos aspectos, a las expresiones que se dibujan en los territorios brasileños, conformando una cartografía simbólica de espacios en la cotidianidad -espacios "indisciplinados"-, ocultos a las miradas "civilizantes". En este contexto, la propuesta de este artículo es presentar la investigación de campo realizada en las regiones de Esmeraldas (Ecuador) y São Paulo (Brasil) en la búsqueda de los aspectos comunes de la religiosidad afrodescendiente por medio de los arrullos ecuatorianos y el candomblé brasileño.
\end{abstract}

Palabras claves: Religiosidad, etnoespacio, etnicidad, expresiones religiosas, resistencias.

Evidence of African origin in the people of Esmeraldas can be found in their religious expressions. Throughout history these elements, possessors of a specific identity, have been the very spaces of resistance to the cultural imposition of colonization. While the majority of the Afro-Ecuadoria population is Catholic, it is possible to find within its religiosity the components of resistance which have remained active, and which are in some respects similar to the expressions found in Brazil, constituting a symbolic cartography of spaces appropriated in daily life - "undisciplined" daily spaces-, hidden from the lances of "civilization". In this context, this article's purpose is to present field research carried out in Esemeraldas (Ecuador) and São Paulo (Brasil) in search of common aspects of Afro-American religiosity. The article is a comparative study of two specific forms, namely, the arrullos of Ecuador and the Brazilian candomblé.

Key words: Religiosity, ethnospace, ethnicity, religious expressions, resistance.

\section{Introducción}

Brasil y Ecuador tienen en común más que la historia de una colonización y la existencia geográfica en el sur de las Américas. Aunque no hay un límite físico entre Brasil y Ecuador, ambos países comparten algunas características, entre las que llama especialmente la atención la presencia -de naturaleza y constitución diversa- de las poblaciones mestizas y de su articulación en tres etnoespacios (Pireto 1994) comunes: el del indígena originario, el del negro africano traído al continente en los barcos de esclavos, y el de los europeos llegados de la península ibérica (Centro Cultural Afroecuatoriano
[CCA] 2002). No obstante, a pesar de la histórica cotidianidad compartida, las interacciones entre indígenas, africanos y europeos han generado diferentes relaciones y realidades socioculturales en Brasil y Ecuador, que van desde una compleja participación en las luchas por la ciudadanía, a la construcción de una religiosidad popular en los dos países. En este sentido, a pesar de observar una matriz común, Brasil y Ecuador se distancian, religiosamente, respecto de su herencia africana, en el ejercicio de cultivar, los descendientes africanos en Brasil, religiones que les acercan a sus antepasados, mientras que los afroecuatorianos se alejan de ellos mediante una profunda evangelización

\footnotetext{
* Centro Universitário Belas Artes de São Paulo. São Paulo, Brasil. Correo electrónico: mr.perez@ucm.es

** Universidad de Cuenca, Facultad de Ciencias Económicas y Administrativas, Proyecto VLIR Migración Internacional y Desarrollo Local. Cuenca, Ecuador. Correo electrónico: piratepitaph@ gmail.com
} 
(Montaño 2002). Al defender la Iglesia católica en ambos países el punto de vista del colonizador -que consideraba las culturas del pueblo negro e indígena inferiores y desprovistas de la presencia de Dios-algunos investigadores señalan, como resultado de esta aculturación, una ausencia de rastro de cultos africanos, de un sincretismo religioso o de un culto activo de matriz africana en Ecuador. La evangelización católica de los negros fue uno de los aspectos que más influyó en la pérdida de las representaciones de origen africano en Ecuador y este aspecto es uno de los que crea una diferencia religioso-cultural con Brasil (Bonfil 1989).

El presente trabajo propone presentar la investigación exploratoria que responde a un enfoque comparativo multisituado (Marcus 1995) en dos espacios concretos: la provincia de Esmeraldas en Ecuador y el estado de São Paulo en Brasil. La investigación tenía por objetivo observar las expresiones religiosas actuales en ambos espacios para conocer si existen elementos comunes a partir de un pasado que acerca a las dos regiones mediante la visibilización de rasgos de religiosidad de matriz afrodescendiente en ambos territorios partiendo de su herencia migratoria africana común. Este estudio se ha basado en las técnicas cualitativas de la observación participante y la entrevista ${ }^{1}$ (en profundidad) para obtener datos que puedan dirigir la interpretación de la información recopilada. Asimismo, el estudio se ha complementado con el análisis de fuentes cuantitativas y cualitativas secundarias: bases de datos, indicadores económicos, sociodemográficos y culturales, y la lectura de obra bibliográfica acerca de la cuestión.

\section{Religiosidad y Resistencia}

En el momento en que el negro venido de África optó por la experiencia cristiana, dentro de un modelo tradicionalmente europeo, en lugar de la resistencia en mantener sus creencias, el negro católico ecuatoriano dejó de vivenciar toda la identidad cultural heredada de África e intentó alejarse de cuestiones raciales como la discriminación y el prejuicio racial. No obstante, mientras el afroecuatoriano acepta la religión europea, el negro de Brasil busca maneras de seguir con sus costumbres e identidad cultural (Adriano 2007). A pesar de todo, sea en Brasil, sea en Ecuador, frente a la imposición europea, el pueblo afro logró rescatar algunas prácticas tradicionales aunque de manera sincrética, frente a las continuas campañas de la Iglesia por suprimirla. Siguiendo esta línea, se puede observar que el pueblo afro es hondamente religioso y que se expresa con fiestas y ritmos, danzas de origen religioso al son de la percusión de los tambores y la existencia de ciertos elementos que son un interesante punto a ser investigado en Ecuador. La población afroecuatoriana, en las últimas décadas, reconoce que su cosmovisión, sus conductas, sus cantos, bailes y religiosidad, están marcadamente influenciadas por unas raíces africanas que generan un sentimiento de unidad y comunidad, independientemente de cuál haya sido su origen étnico (CCA 2002).

En este contexto, las huellas de los orígenes africanos en la expresión religiosa de los pueblos esmeraldeños -es en la población más alejada de las grandes ciudades en donde más se han conservado estas prácticas y creencias ligadas a las tradiciones africanas, como la existencia de fuerzas sobrenaturales que actúan en la vida cotidiana de las personas- se conforma como un elemento de resistencia a la colonización. Aunque la mayor parte de la población afroecuatoriana practica actualmente la religión católica, pueden percibirse, en su religiosidad, algunos elementos de origen africano, en los que suele jugar un papel relevante los cantos y la música. Estos elementos poseen una identidad muy específica, siendo posible, por un lado, rastrear los componentes activos de las resistencias y, por otro, pensar que todavía hay aspectos importantes de la cultura religiosa afroecuatoriana que se acercan a Brasil en su origen africano (Fanon 1974).

La cultura afro en Brasil y Ecuador se ha transmitido de generación en generación por la tradición oral. Mediante este mecanismo se ha creado un sincretismo entre las nociones de las divinidades del catolicismo y las creencias animistas. Aunque no se conocen manifestaciones exclusivas de religiones afroamericanas, existe la posibilidad de reconocer los elementos incorporados por cimarrones y esclavos, quienes mimetizaron sus rituales y deidades primero como estrategia de supervivencia y, posteriormente, como parte de su propia identidad. Asimismo, el interés de reconocer, sea en el plano del pensamiento como en la praxis cotidiana de los afroecuatorianos, categorías como el bien y el mal, lo natural y lo sagrado, la vida y la muerte, el espíritu y la materia, lo real y lo imaginario, que constituyen rastros de una religiosidad no europea y, al mismo tiempo, elementos de resistencia colonial, pueden acercarnos a espacios cultural-religiosos 
etnificados en el ser y en el hacer que escaparon a la aculturación colonial (Zahan 1980).

\section{El poder del ritual y la ritualidad del poder como espacio de resistencia en Ecuador y Brasil}

Tanto en la religiosidad popular afro en Brasil como en Ecuador pueden encontrarse rasgos comunes en las expresiones religiosas. Uno de los más significativos es la inexistencia de sacerdotes en las reuniones populares y la prohibición de participar de los oficios de esa religiosidad en los espacios de cultos católicos que originó que estas expresiones se produjeran en el espacio público ante el no reconocimiento de la Iglesia católica. Así, durante siglos, los pueblos afrodescendientes han continuado con sus expresiones religiosas (católicas) populares en los espacios públicos posibilitando una manera de mantener la memoria de la cultura africana ${ }^{2}$ por medio de su vivencia de la fe católica. Con un ritmo marcado por instrumentos de percusión-marimbas, bombos, cununos y guasás, en Ecuador, y atabaques, cachichis agogôs e xequerês, en Brasil-, con bailes intensos y con ropas que recuerdan los trabajos cotidianos que realizaban en un pasado rural, las y los afrodescendientes reivindican, igual que antaño, su identidad ${ }^{4}$, su presencia y su existencia. No obstante, resulta un ejercicio difícil de profundizar en el entramado de símbolos y representaciones africanas e identificar rasgos específicos de un determinado pueblo o lugar. La memoria que se tiene de África es vaga, genérica e indefinida en muchas ocasiones:

A cultura africana que assim vai se diluindo na formação da cultura nacional corresponde a um vastíssimo elenco de itens que abrangem a língua, a culinária, a música e artes diversas, além de valores sociais, representações míticas e concepções religiosas. Mas, fora do campo religioso, nenhuma das instituições culturais africanas logrou sobreviver. Ao contrário, cada contribuição é o resultado de um longo e lento processo de diluição e apagamento étnico a tal ponto que, diante de um determinado traço cultural, embora podendo reconhecer uma origem africana genérica, ainda assim é difícil, quando não impossível, identificar o povo ou nação de que provém. Tudo é simplesmente África (Prandi 2000:58-59) ${ }^{3}$.
A pesar de esta memoria vaga y genérica, lo que puede apreciarse en la religiosidad popular afro vivida en los espacios públicos y sin la organización de la institución católica es la vivencia de un espacio compartido que, por constituirse de esta forma, se vuelve realidad, persistencia y resistencia de una cultura en el tiempo y espacio. Así, la religiosidad popular logra mantener viva rasgos de la cultura afro por su vivencia colectiva.

En un mundo globalizado y posmoderno - $\mathrm{O}$ sobremoderno- (Augé 2012), donde las relaciones e interacciones con los espacios y sus elementos cambian y se transforman velozmente, la eficiacia simbólica del poder se acrecienta (Balandier 1994). Mediante imágenes, símbolos, ritos, ceremonias y otras representaciones, el ejercicio y la demostración del poder se asientan en la cotidianidad en el marco de una modernidad mediáticamente "anestesiada" (Balandier 1994) y socioeconomicamente aterrorizada por perder los privilegios "obtenidos". En este sentido, las expresiones populares cobran una especial importancia creando espacios de ruptura en estas dinámicas hegemónicas y conformando lugares de contrapoder y reivindicación. Mediante varios rituales cotidianos, las expresiones religiosas afrodescendientes en Ecuador y Brasil van a conformarse como reivindicadoras de una identidad tradicionalmente despreciada desde las colonias, erigiéndose ahora como portadoras de una historia no contada, de una historia vivida que demanda un lugar que siempre le fue (y muchas veces le es) negado.

Los rituales religiosos populares afrodescendientes, a pesar de tener tantos elementos como contenidos casi estrictamente católicos -por la colonización europea-, son, en sí mismos, una forma de resistencia que nace históricamente por la imposibilidad de las y los negros de asistir a los ritos católicos. En este sentido, aunque las y los afrodescendientes cultiven un culto a los santos católicos, las manifestaciones, al realizarse por medio de bailes y cantes, hacen referencia a las herencias culturales afro por medio del uso de instrumentos musicales de percusión y ropas coloridas que hacen del rito una expresión "más exuberante". No obstante, "africanizarse" es una idea de los grupos afros militantes actuales y no de los espacios populares. La población más pobre se encuentra enfrentada a un profundo prejuicio de sí mismo, ya que es continuamente atacada y expuesta al ideal "blanco" y sus representaciones 
estéticas y emocionales que dictaminan lo que es bello y correcto en el hacer y el sentir.

En Ecuador y Brasil, aunque lo afro posee una matriz común, las realidades conformadas diacrónicamente son muy diferentes. En el caso de Brasil, la identidad étnica de negros esclavos y negros libres se mantuvo hasta fines del siglo XIX, momento en el que la formación de la sociedad de clases, ya bajo la República (República Vieja de 1889), lograron que las organizaciones de corte estamental étnico fueran perdiendo cada vez más fuerza y sentido, siendo muchos aspectos de las culturas africanas absorbidas por la cultura nacional -la que era primordialmente blanca, europea y cristiana-. En este sentido, preservar aquello que era africano requería destruir o disfrazar precisamente el origen y los rasgos de "lo negro", en un proceso de "blanqueo" que alcanzó a todas las áreas (Herbst 2003). Sin embargo, a mediados del siglo XIX, con la presencia de esclavos, negros libertos y sus descendientes en las grandes ciudades, la población negra tuvo mayores posibilidades de interacción entre sí, mayor libertad de movimiento y mayor capacidad de organización pudiendo congregarse en residencias colectivas concentradas en barrios urbanos donde estaba su mercado de trabajo, en una época en que las tradiciones traídas de África estaban vivas como consecuencia de la reciente llegada. Se creó entonces en Brasil lo que tal vez sea la única reconstrucción cultural "de negro" capaz de preservarse hasta la actualidad: la religión afrobrasileña (Prandi 2000).

La religión afrobrasileña no está institucionalizada y tampoco es unitaria. Se conforma, entonces, como sincrética, fruto de la mezcla de culturas y etnias africanas, indígenas y europeas. El candomblé ${ }^{5}$, por ejemplo, es una de las religiones de matriz afro de Brasil que más se preocupa por mantener viva África en el continente americano. El candomblé es la religión conformada en Brasil en el siglo XIX por medio de la diáspora de diferentes pueblos africanos. Conformado originalmente como resultado de la expresión religiosa de los esclavos, el candomblé se articuló durante siglos bajo presiones que podrían haber conducido a su extinción. Sin embargo, puede observarse, en la actualidad, que no solo ha sobrevivido sino que se ha expandido, influenciando la religiosidad católica popular en Brasil y dando origen a otras religiones sincréticas, como la umbanda ${ }^{6}$. No obstante, para que esta religión pudiera seguir con vida fue necesario un largo proceso de resistencia y reproducción para preservar y mantener sus secretos, sus ritos y sus mitos, claves fundamentales de su tradición. Siguiendo "la África antigua", el candomblé es una religión de tradición oral, en la que sus fundamentos se transmiten de generación en generación mediante la interacción del grupo que lo conforma y que se autodenomina familia de santo (Alves y Pérez Gañán 2014).

Junto a la expresión de la religiosidad, en las grandes ciudades de Brasil del siglo XIX surgieron grupos que recreaban cultos religiosos que reproducían no solo la religión africana, sino también otros aspectos de su cultura en África: una memoria cultural. Aproximadamente $45 \%$ de la población brasileña tiene origen afro, siendo este elevado número uno de los elementos más relevantes para transmitir los rasgos de la cultura afro en el país. Sin embargo, la vivencia colectiva de la religión, en Brasil, se erige como una interacción fundamental no solo para mantener la cultura africana viva en la religión, sino también en la cultura material, en las palabras, la comida, la ropa e incluso en una estética presente en muchas partes de Brasil.

En el caso ecuatoriano, por otro lado, la asimilación tan notable por parte del catolicismo de las comunidades afrodescendientes ha impedido la conformación de una conciencia de resistencia, ya que el intento de estas comunidades de ser parte del catolicismo supeditó la resistencia a la aceptación como miembros de la Iglesia. Mientras en Brasil nació una religión de matriz afro y que pretende mantener la memoria de África viva entre los afrodescendientes, en Ecuador la asimilación del catolicismo por parte de la población afro hizo surgir una manifestación religiosa propia: los arrullos.

Los arrullos, derivaciones de las canciones de cuna, se presentan en Esmeraldas (la provincia de Ecuador con más población afrodescendiente) como expresiones músico-religiosas que la población entona con la intención de crear vínculos entre lo humano y lo divino por medio del cununo, el guasá y el bombo, instrumentos musicales que arrullan a los santos católicos. Así, los arrullos son legados espirituales de poblaciones africanas y hoy constituyen una manera de reconstruir la memoria cultural de los antepasados e incluso se erigen como elementos que recuerdan la resistencia a la esclavitud. Estos poemas-musicales enriquecen el día a día al dar sentido de trascendencia a la vida y a la muerte, al registrar la historia y enaltecer la 
experiencia espiritual. Los arrullos son una importante expresión de la mezcla cultural existente en el norte de Ecuador, ya que al mismo tiempo que la música está imbuida de fuertes rasgos afro, también es posible encontrar las herencias de la colonización en la presencia de la poesía española tradicional, como las coplas, fundamentales para los arrullos. Edy Obando, uno de los arrulladores (y sociólogo) entrevistado en Esmeraldas al hablar sobre los arrullos señala:

Fundamentalmente el arrullo es un misticismo de gente negra, justamente la gente negra comienza ese su folklor... porque al mismo tiempo que está cantando el arrullo, puede expresar el movimiento folklórico como si estuviera bailando la marimba, y la gente se alegra y mueve los codos, mueve las manos... y bueno, en el arrullo tiene que haber una ponedora (una mujer que pone las coplas que serán seguidas por los otros devotos) [...] la ponedora va poniendo coplas, va incrementando coplas, entonces es un valor cultural muy atractivo esa cosa, porque son gente generalmente no estudiada, no letrada, sin embargo, tienen un léxico en ese campo de sus arrullos que riman, porque tiene que haber una rima en el arrullo (Edy Obando comunicación personal 2014).

De igual modo, al hablar acerca de la importancia del arrullo como expresión cultural y de resistencia negra -aunque dentro del catolicismo-, el mismo arrullador pone énfasis en los elementos "indisciplinados" y rebeldes de la población afrodescendiente desde el principio:

[...] No sé si ya han escuchado la expresión 'la merienda de negros'... 'la merienda de negros' es una mesa donde una tribu nos reunimos, y aquí en esa mesa está todo lo que podemos servir. Pero no se queda en la merienda de negro solo de comer, la merienda de negro termina en ir ese grupo cantando, pero cantando, qué... Esto, el arrullo. El arrullo, porque ellos no tenían la oportunidad de asistir a los cultos y de ahí nacen el baile de la marimba, el color, la forma, la expresión de la marimba, y de ahí nace la manifestación de aquí... el arrullo (Edy Obando comunicación personal 2014).

La marimba, tradicional baile y música afroecuatoriano de la provincia de Esmeraldas, aunque no posea rasgos explícitamente religiosos, se encuentra sociopolíticamente con los arrullos por ser una de las manifestaciones culturales ecuatorianas que intenta mantener vivos los rasgos afro: "El papel de la marimba en el movimiento afroecuatoriano ha sido doble: el de símbolo general de la identidad étnica y de la cultura afrodescendiente y el de recurso performativo orientado a fines específicos (Ritter 2010:111).

Un factor importante que explica esta característica del caso ecuatoriano, en comparación con Brasil, responde al bajo porcentaje poblacional afro en Ecuador, que solo alcanza 7\% de la población. Otro factor que incide en esta asimilación cultural se refiere a las circunstancias de la llegada de los africanos a Ecuador en comparación con Brasil. La referencia en los libros de historia, relativas a la diáspora afro en Ecuador, señala un naufragio en el siglo XVI de un barco que conducía a un grupo de esclavos de Panamá a Lima y que encalló en la costa esmeraldeña, en el norte de Ecuador. Un grupo de hombres y mujeres supervivientes se escaparon y se establecieron en libertad y se unieron con la población indígena local. Aunque hubiera otros esclavos negros en Ecuador y existiera un fomento de la institución esclavista en la región de Esmeraldas, no hay registros de un intenso tráfico entre Ecuador y África en comparación con Brasil, donde el tráfico de esclavos africanos duró tres siglos (del siglo XVI al XIX) y superó los once millones de esclavos (García de Polit 1992). Así, la población descendiente de africanos, en Ecuador, por ser numéricamente pequeña en el momento de la abolición de la esclavitud, no encontraba una manera de integrarse socialmente más que por medio de una inserción en la cultura dominante, la blanco-mestiza y en su religión, la religión católica. No obstante, como se ha señalado anteriormente, los negros recién libertos no podrían frecuentar las iglesias, espacio de la sociabilidad de los blancos, viéndose obligados/as a expresar su devoción en los espacios fuera de las iglesias y sin la presencia de los curas católicos. De esa manera nace otro tipo de culto católico, distinto del institucional, con otros símbolos que muchas veces mantienen vivos rasgos de la cultura afro, pero que sirve para 
resignificar el culto que ahora es católico: "La tradición, el arrullo nace para arrullar, para adorar a los santos [...] generalmente la tradición de los arrullos es de gente católica. No hay adventistas, no hay evangelistas, no comulgan con eso" (Edy Obando comunicación personal 2014). Rosa Wila, esmeraldeña arrulladora y marimbera también hace hincapié en mostrar el catolicismo de los arrullos: "Aquí [en Esmeraldas] hay evangélicos y católicos. Hay dos religiones aquí. Yo soy católica. Para nosotros, católicos religiosos, la música está en los arrullos (Rosa Wila comunicación personal 2014).

Siguiendo las ideas de Balandier (1994) respecto de la representación del poder en los ritos y su puesta en escena, observamos la fuerza de los símbolos africanos presentes en las expresiones religiosas afrodescendientes en Brasil y Ecuador articuladas desde el propio emplazamiento hasta la sofisticación en sus prácticas. Estos rituales, muy atractivos tanto para adeptos como para no adeptos por los métodos artísticos que utiliza, convierten las ceremonias de dichos rituales en una fiesta con un propósito concreto: una asimilación sencilla. De esta forma:

La categoría de lo sagrado rompe la inercia de los soportes materiales determinando sus funciones representativa y simbólica, así como sus propiedades que, por consiguiente, pasan a cumplir el papel de mediadores entre los practicantes y sus creencias. Así, lo sagrado actúa también como eje articulador y expresivo en las formas que adquieren los mismos, una vez que siendo apropiados como medios de comunicación, expresan y revelan desde las necesidades, propósitos y deseos de los practicantes, hasta la concepción que tienen del mundo, del hombre y de sus relaciones con estas religiones. Y si entendemos el fenómeno estético como resultado de la relación sujeto-objeto en un contexto donde ambos son copartícipes activos, observaremos que las formas de los soportes materiales revelan los respectivos universos estéticos [...] Universos que no es posible apreciar en los objetos aislados, sino cuando estos se insertan en los espacios ideo-físicos de sus respectivas religiones (Hernández 2008:1).

A este proceso perceptivo se suman el lenguaje ritual, la música, los cantos y los bailes, creando una atmósfera que altera la percepción habitual del tiempo. En estos espacios rituales el tiempo tiene su propia lógica. Nada está precalculado; todo depende de las exigencias de cada tipo de actividad y de cómo tendrá lugar. Este "fenómeno estéticolitúrgico" (Hernández 2008) es para el adepto una acción estética ininterrumpida que va a crear, en cada una de sus manifestaciones, un sentido y un significado concreto.

\section{Desafíos actuales de la religiosidad popular afroecuatoriana y afrobrasileña}

Tanto en Brasil como en Ecuador acercarse a África es un intento de la población militante de sacar de un olvido generalizado a la población afroecuatoriana sobre los elementos de la herencia cultural africana que siguen vivos en su cultura y de tratar de acabar con los prejuicios "de lo afro" de los que está impregnada la cotidianidad social. En el caso especial de Brasil:

[...] trata-se da adesão a uma estética da negritude - vestuário, penteados, adereços, ditos afro. Além de sua própria imagem, a adesão deve passar pela valorização e mesmo adoção de elementos da "cultura africana", tais como música, dança, jogos e até hábitos alimentares, traduzidos nos jornais em receitas atribuídas aos antigos descendentes de escravos (Maués 1991:127).

Asimismo, Domingues señala, en relación con el proceso político significante de la visibilización de los elementos afrodescendientes en las expresiones religiosas:

\section{[...] Até no terreno religioso houve um pro- cesso revisionista. Se nas etapas anteriores o movimento negro era notadamente cristão, impôs-se a cobrança moral para que a nova geração de ativistas assumisse as religiões de matriz africana, particularmente o can- domblé, tomado como principal guardião da fé ancestral (Domingues 2007:116).}

Sin embargo, esta militancia situada muchas veces en la academia o en otros grupos de poder, no se corresponde con las representaciones de las personas que participan y mantienen vivas estas expresiones religiosas. En las entrevistas realizadas para esta investigación fue posible percibir en el 
discurso de las personas responsables de los cantos, los bailes y los rezos en las expresiones religiosas la falta, en general, de una consciencia de los elementos afro presentes en los ritos practicados.

En Ecuador, especialmente, fue común escuchar decir a la gente que las manifestaciones religiosas populares eran católicas y que lo único que había de rasgo africano era la utilización de instrumentos de percusión en la música. Cuando se preguntaba a las y los informantes respecto de las ropas -que además presentaban características muy cercanas entre Brasil y Ecuador, lo que puede ser visto como un marcador de un pasado común-, sus colores, las formas de las faldas de las mujeres, los collares o los pañuelos utilizados en la cabeza, la explicación dada era exclusivamente estética y no un rasgo de cultura afro que sigue viva en estas prácticas: "Ellas (las ponedoras de arrullos) se visten sus vestimentas, su trapo en la cabeza afro. De hecho una representación de la identidad afro es el turbante" (Edy Obando comunicación personal 2014).

Asimismo, coexiste con esta ausencia de conciencia otro discurso generalizado acerca de la pérdida de las tradiciones y la herencia africana en la juventud. Las personas mayores responsables de cantar, tocar y bailar se quejan constantemente de que las generaciones jóvenes ya no se interesan en mantener estas expresiones vivas, en conocer la música ni en aprender los bailes: "Aquí que hay tantos jóvenes... los que aprenden a bailar en el conservatorio, nunca se los ve bailando, yo creo que les da vergüenza. Pero para bailar la música que hay ahora, el reguetón, en la calle se los ve bailando" (Rosa Wila comunicación personal 2014).

Por ello, existe, entre las generaciones mayores, un temor creciente de la pérdida de estas expresiones religiosas y la memoria afro que en ellas se inscribe:

[...] Eso que estamos hablando... se va perdiendo porque la nueva generación no va a entrar... a unos 20, 25 años no vamos a encontrar, porque Papa Roncon y esa turma ya va a estar muerto. Rosa Wila también. Petita Palma también, y yo también, que soy de una nueva generación comparado a ellos. (Edy Obando comunicación personal 2014)

No obstante, al asistir a varias reuniones religiosas populares en Brasil y en Ecuador pudo observarse el gran número de niños/as que se acercaban a participar del rito religioso. Pareciera que el ritmo de la modernidad ha impregnado también la vida de las y los mayores que hoy se interesan más en ver la televisión o seguir con sus trabajos (como se pudo reconocer repetidamente durante las observaciones en campo) en lugar de enseñar a las y los niños las tradiciones. Así, el contacto de los/as jóvenes con las manifestaciones culturales y religiosas de herencia africana se reduce cada día menor por una falta de responsabilidad compartida entre las distintas generaciones. Finalmente, las personas mayores participantes de las expresiones religiosas culpan el desinterés que perciben en los jóvenes a una falta de un apoyo desde las instituciones públicas en el mantenimiento de las tradiciones.

La nueva juventud de ahora va viendo con tristeza que esta riqueza cultural se ha hecho muy comercial y como no tenemos organismos gestores que organicen la cultura, porque el municipio tiene que tener, así como tenemos la escuela de futbol, que se lo estimula, se da estudio, se les paga, se les da casa y todo, así era que ser con la cultura, habría gente que estuviera ahí. Pero salen esos niños a ensayar marimba, a ensayar folklor, con su propio pasaje, van y con sus propios recursos van a regresar. Quién los estimula económicamente? [...] creo que esto ha influido de que vayamos perdiendo este tipo de cosas (Edy Obando comunicación personal 2014).

A pesar de ello, y en contradicción con la idea de una falta de apoyo institucional, se presenciaron, tanto en Ecuador como en Brasil, algunos actos organizados desde las instituciones públicas para mostrar estos elementos de la tradición afro a los que acudían todas/os los principales exponentes de estas expresiones culturales, muchos/as de los cuales afirmaban (en las entrevistas) que no existía ningún apoyo, a pesar de ser "contratados/as" periódicamente y haber sido promocionados en diferentes lugares de Ecuador y el mundo.

Petita Palma (arrulladora y marimbera) es internacional, Petita Palma ha formado escuela de marimba, pero que ocurre? Ella es una señora que le invitan a Colombia, Perú, EE.UU., pero va ella entonces la nueva juventud de ahora va vendo con tristeza que es esta riqueza cultural se ha 
hecho muy comercial [...] (Edy Obando comunicación personal 2014).

En este sentido, la negación de esta ayuda institucional parecía estar relacionada con la forma en la que las instituciones representaban estas expresiones culturales y religiosas mediante una "folklorización" (Martí 1996) y una profesionalización del acto en una estética de formas y colores que alteraban el significado de lo representado en pos de una representación institucional de la cultura y no una expresión de la cultura misma. De este modo, aunque algunos/as representantes de las expresiones religiosas afrodescendientes se oponían y criticaban esta forma institucional de representar la cultura, la mayoría eran partícipes de los eventos concertados, ya que siguen otorgando estatus, visibilización y, en muchos casos, sustento material: "Unas veces me buscan a cantar. Yo canto desde las nueve hasta las dos de la mañana, 50 dólares" (Rosa Wila comunicación personal 2014).

\section{Conclusiones}

La reconstrucción de la cultura religiosa africana en Brasil y Ecuador fue orientada, no sin que ocurrieran cambios y pérdidas, por un proceso que dejaba entrever el hecho de dar sentido a la memoria y a la identidad negra en la diáspora. La reconstrucción del pasado que orienta la construcción de la identidad se hace así a partir de la cultura brasileña y no del verdadero y perdido origen étnico, familiar y, en última instancia, racial. Incluso cuando el sujeto se expresa para afirmar su negritud, su condición africana, no le resta a él más que hacerlo como brasileño/a. Aunque el pasado ancestral perdido sea África pluriétnica, multicultural, el pasado recuperable es aquel que Brasil y Ecuador lograron incorporar en la construcción de una nueva civilización, pasado que solo puede ser reinventado: una memoria de reparación recreada.

Para los pueblos africanos, antes del contacto con la cultura europea, el tiempo es cíclico, no lineal ni histórico. El presente es nada más que una repetición del pasado, de algo que ya sucedió y es conocido. Esos acontecimientos del pasado están vivos en los mitos, que hablan de grandes aventuras, actos heroicos, descubrimientos y todo tipo de eventos de los cuales la vida presente sería una repetición continua. El mito habla del pasado remoto que explica la vida en el presente. El tiempo mítico es solo el pasado distante, donde se encuentra la verdad del presente. El tiempo del mito es el tiempo de los orígenes. Ese pasado remoto, de narrativa mítica, es colectivo y es transmitido de generación en generación -por medio de la oralidad-, con la intencionalidad de articular un sentido general de la vida y de construir una identidad grupal con normas y valores que se extrapolen más allá de la religión conformando un todo con la sociedad.

En las expresiones religiosas populares afrodescendientes en Brasil y Ecuador cuando la negra o el negro comienzan a cantar y a bailar, la identidad del pueblo africano aflora para mostrarse vivo en un ritual que transporta el pasado hacia el presente, en una representación en carne y hueso de la memoria colectiva. En esta puesta en escena se concentra el poder y la memoria de resistencia. Sin embargo, estas resistencias se enfrentan a tres retos claves para su supervivencia: la necesidad de tomar consciencia de "lo afro", el compromiso de implicar a las nuevas generaciones en el mantenimiento de sus prácticas y la responsabilidad de que estas expresiones religiosas no queden ancladas exclusivamente en unos espacios institucionales que la moldean, la representan y la resignifican según sus intereses.

\section{Agradecimientos}

Pablo Minda, Arquímedes Simisterra, Papá Roncón, Rosa Wila, Edy Obando (personas entrevistadas en Esmeraldas), Centro Universitário Belas Artes de São Paulo, Proyecto VLIR Migración Internacional y Desarrollo local de la Universidad de Cuenca. 


\section{Referencias Citadas}

Adriano, L.

2007 Afroecuatorianos. Revista Pacificard 60:60-61, Banco del Pacífico, Ecuador.

Augé, $\mathrm{M}$.

2012 Futuro. Adriana Hidalgo, Buenos Aires.

Balandier, G.

1994 El Poder en Escenas: de la Representación del Poder, al Poder de la Representación. Traducido por M. Delgado Ruiz. Paidós, Barcelona

Bonfil, G.

1991 La teoría del control cultural en el estudio de procesos étnicos. Estudios sobre las Culturas Contemporáneas Vol. IV, 12:165-204, Universidad de Colima, México D.F.

Centro Cultural Afroecuatoriano (CCA). 2002. Historia del Negro del Ecuador. IFA, Quito.

Domingues, $\mathrm{P}$.

2007 Movimento negro brasileiro: alguns apontamentos históricos. Tempo Vol. XII, 23:100-122, Universidad Federal Fluminense, Río de janeiro.

Fanon. F.

1973 Piel Negra Máscaras Blancas. Traducido por A. Abad. Abraxas, Buenos Aires.

García de Polit, R.

1992 "El sistema esclavista en la época del general Florez, 1840". En El Negro en la Historia. Centro Cultural Afroecuatoriano, Quito.

Herbst, M.

2003 El concepto de identidad iberoamericana como elemento posibilitador del discurso indigenista. Tesis doctoral. Universidad de Georgia, Athens.

Hernández, J.L.

2008 La santeríay el candomblé: dos universos semejantes. Encuentro 48-49. Disponible en: http://www.Cubaencuentro.com/revista/ revista-encuentro/archivo/48-49-primavera-verano-de-2008/ la-santeria-y-el-candomble-dos-universos-semejantes-97196 (1 de febrero de 2015)

Martí, J.

1996 El folklorismo. Uso y abuso de la tradición. Ronsel S.L, Barcelona

Marcus, G.

1995 Ethnography in/of the World System: The Emergente of Multi-sited Ethnography. Annual Anthropological Review, 24: 96-117.

Maués, M.A.M.

1991 'Da 'branca senhora' ao 'negro herói': a trajetória de um discurso racial”, Estudos Afro-Asiáticos, 21:119-130, Rio de Janeiro.

Montaño, J.E.

2002 Al ritmo de Marimba. Terra Incógnita 17. Disponible en: http://www.edufuturo.com/educacion.php?c=1146 (28 de enero de 2015)

Pireto Castillo, D.

1994 La vida Cotidiana. Silva, Quito.

1990 El autodiagnóstico comunitario. Quipus, Quito:

Prandi, R.

2000 De africano a afro-brasileiro: etnia, identidade, religião". Revista USP 46:52-65. São Paulo.

1991 Os Candomblés de São Paulo: a Velha Magia na Metrópole Nova. Hucitec e Edusp, São Paulo.

Ritter, J.

2010 "Hibridez, raza y la marimba esmeraldeña: repensando las fusiones musicales en el pacífico negro ecuatoriano", Ensayos. Historia y teoría del arte, Universidad Nacional de Colombia, 18:98-121, Bogotá D. C.

Rivera Cusicanqui, S.

2010 Ch'ixinakax utxiwa: una reflexión sobre prácticas y discursos descolonizadores. Tinta Limón, Buenos Aires.

Zahan, D.

1980 Espiritualidad y Pensamientos Africanos. Ediciones Cristiandad, Madrid.

\section{Notas}

1 Se realizaron 20 entrevistas a población compuesta por hombres y mujeres, de entre 20 y 80 años en distintos espacios en la provincia de Esmeraldas en Ecuador y São Paulo en Brasil. De igual modo se establecieron contactos para entrevistas en organismos públicos y privados como universidades, asociaciones e instituciones religiosas con el fin de recabar información relevante desde diferentes ámbitos. El desarrollo del trabajo de campo se llevó a cabo en la provincia de Esmeraldas durante los meses de julio y agosto de 2014.

2 Aunque muchos/as de los practicantes de estos ritos no tienen una conciencia de reivindicación.

3 "La cultura africana diluida en la formación de la cultura nacional se corresponde con un vasto conjunto de símbolos que abarcan la lengua, la gastronomía, la música y diversas artes, además de valores sociales, representaciones míticas y concepciones religiosas, conservadas no solo a partir de una matriz africana única, sino de varios, de múltiples orígenes, provenientes de diferentes pueblos africanos. Sin embargo, fuera del campo religioso, ninguna de las instituciones culturales africanas logró sobrevivir con estructuras propias. Por el contrario, cada contribución es el resultado de un largo y lento proceso de dilución y borrado étnico hasta el punto de que, a pesar de ser capaces de reconocer ciertos rasgos culturales y atribuirles un origen africano genérico, resulta difícil, cuando no imposible, identificar el pueblo o nación de que se trata. Todo es, simplemente, África" (Traducción de las autoras).

4 Una identidad dinámica que incorpora elementos católicos no en una hibridación equilibrada, sino en una relación conflictual que construye dicha identidad (Rivera Cusicanqui, 2003).

5 El candomblé es una religión animista afrobrasileña. Puede llevar otros nombres dependiendo de la región de Brasil en la que se asiente. También es llamado: macumba, xangô o tambor-de-mina.

6 Umbanda es una religión brasileña formada por elementos de otras religiones como el catolicismo o el espiritismo que sigue sumando elementos de la cultura africana y la indígena. 
